\title{
Systemic 7-methylxanthine in retarding axial eye growth and myopia progression: a 36-month pilot study
}

\author{
Klaus Trier • Søren Munk Ribel-Madsen • \\ Dongmei Cui • Søren Brogger Christensen
}

Received: 19 June 2008 / Accepted: 22 September 2008/Published online: 4 November 2008

(C) The Author(s) 2008. This article is published with open access at Springerlink.com

\begin{abstract}
The adenosine antagonist 7-methylxanthine (7$\mathrm{mx}$ ) works against myopia in animal models. In a clinical trial, 68 myopic children (mean age 11.3 years) received either placebo or 7-mx tablets for 12 months. All participants subsequently received $7-\mathrm{mx}$ for another 12 months, after which treatment was stopped. Axial length was measured with Zeiss IOL-Master and cycloplegic refraction with Nikon Retinomax at $-6,0,12,24$, and 36 months. Axial growth was reduced among children treated with 7-mx for 24 months compared with those only treated for the last 12 months. Myopia progression and axial eye growth slowed down in periods with 7-mx treatment, but when the treatment was stopped, both myopia progression and axial eye growth continued with invariable speed. The results indicate that $7-\mathrm{mx}$ reduces eye elongation and myopia progression in childhood myopia. The treatment is safe and without side effects and may be continued until 18-20 years of age when myopia progression normally stops.
\end{abstract}

Trial registration: ClinicalTrial.gov. Registration number NCT00263471. www.clinicaltrials.gov.

K. Trier $(\triangle) \cdot$ S. Munk Ribel-Madsen

Trier Research Laboratories,

Tingskiftevej 6 ,

2900 Hellerup, Denmark

e-mail: ktrier@dadlnet.dk

D. Cui

State Key Laboratory of Ophthalmology,

Zhongshan Ophthalmic Center, Sun Yat-sen University,

Guangzhou, China

S. Brøgger Christensen

Department of Medicinal Chemistry,

Faculty of Pharmaceutical Sciences, University of Copenhagen,

Copenhagen, Denmark
Keywords 7-methylxanthine .

Adenosine receptor antagonist $\cdot$ Myopia $\cdot$ Clinical trial

\section{Introduction}

Normally, the axial length of the human eye increases from $17 \mathrm{~mm}$ at birth to $24 \mathrm{~mm}$ at 14 years of age. From an initial hypermetropia the refraction gradually changes toward emmetropia. It has been hypothesized that a growth-control mechanism exists, which can either accelerate or slow down axial growth in response to defocusing of the retinal image during the period of normal eye growth. Results from experimental myopia in mammals suggest that this mechanism works by regulating the scleral extensibility through complex changes in the synthesis and degradation of extracellular matrix components [1-3].

In myopic children an excessive eye elongation is typically seen from age 6 years until 20 years. The axial length will then be in the range of 24-28 mm. Until the age of 14 years, the increase in myopia is approximately linear [4], after which a slow deceleration is seen [5]. With maturity, an increase in collagen cross-linking occurs [6], which probably explains the gradual stabilization of myopia. The myopic eye differs in shape from normal eyes, because the increase in length ( $0.35 \mathrm{~mm}$ per diopter) is greater than the increase in height (0.19 $\mathrm{mm}$ per diopter) and width $(0.1 \mathrm{~mm}$ per diopter), resulting in the characteristic "egg-shape" of highly myopic eyes [7].

With increasing axial length there is an increased risk of potentially blinding complications later in life, such as retinal detachment, macular degeneration, or glaucoma. About $23 \%$ of all cases of retinal detachment occur in eyes with myopia of more than -6 dioptres [8]. This underlines 
the importance of finding an efficient and safe way to prevent excessive axial elongation.

There is today no treatment that efficiently and without side effects controls the progression of myopia [9]. Topically applied muscarine antagonists, like the nonselective antagonist atropine, and the M1 selective antagonist pirenzepine have been shown to reduce myopia progression and axial eye growth [10-12]. The mechanism of action of atropine and pirenzepine has not been established, but it is assumed that it is independent of their action on accommodation, and that it may depend on receptors in the retina or the sclera [13]. Reduced accommodation and dilation of the pupil, however, remain a problem both with atropine and to a lesser degree with pirenzepine.

The biomechanical properties of sclera are determined by the contents and organization of proteoglycans and collagen [14]. Collagen accounts for about $80 \%$ of the dry weight of sclera [15]. It is known that plastic deformation (creep) of tissues is directly related to the proportion of small diameter fibrils [16]. The diameter of the collagen fibrils in sclera from myopic eyes is reduced compared to normal eyes, as are the contents of collagen and glycosaminoglycans [17].

Experimental myopia in mammals is accompanied by a decrease in the scleral content of proteoglycans and collagen [18], with reverse changes taking place during recovery [19]. In mammalian models of high myopia, a thinning of the posterior sclera and an increased number of small diameter collagen fibrils in posterior sclera is found [20,21].

Treatment of young rabbits with a metabolite of caffeine and theobromine, 7-methylxanthine (7-mx), increases the thickness of the posterior sclera, increases the content of collagen-related amino acids in posterior sclera, and at the same time increases the diameter of the collagen fibrils in the posterior sclera [22]. Recently, 7-mx has been shown to reduce the amount of myopia and eye elongation induced by form deprivation in guinea pigs and to counteract the thinning of posterior sclera and of collagen fibrils induced by form deprivation [23].

Theobromine and its metabolite, 7-mx, both have very low toxicity [24, 25] and no carcinogenic effects [26]. The aim of this study was to test whether $7-\mathrm{mx}$ is useful against axial elongation and myopia progression in childhood myopia.

\section{Subjects and methods}

\section{Participants}

One hundred seven children, aged $8-13$ years, with a minimum myopia of -0.75 diopters (cycloplegic) in one eye were screened using two subject visits with an average interval of 6 months. Eighty-three were found to have an average axial growth rate of $0.075-0.39 \mathrm{~mm}$ per 6 months, and were enrolled in the study. The low cut-off was chosen in order to exclude children with a normal or close to normal axial growth rate. The high cut-off was chosen in order to exclude atypical cases with an extremely fast progression. The normal axial growth rate in children of this age-group is around $0.05 \mathrm{~mm}$ per 6 months [27].

All participants were Danish. Children using soft contact lenses were accepted. All children used single vision lenses. The degree of under-correction was not assessed, but the parents were encouraged to have the children's correction adjusted at regular intervals.

The study followed the tenets of the Declaration of Helsinki. Informed consent was obtained from the participants and their parents. Approval was obtained from the Danish Medicines Agency and the Ethics Committee for the municipality of Copenhagen and Frederiksberg. The trial was registered at www.clinicaltrials.gov, Reg.NCT00263471.

\section{Intervention}

During a 12-months placebo-controlled trial, participants received one tablet every morning. The tablets had a diameter of $12 \mathrm{~mm}$ and a thickness of $3 \mathrm{~mm}$. Active tablets contained $400 \mathrm{mg}$ 7-mx, placebo tablets only standard filling and binding substances.

Peak serum concentration after an oral dose of $400 \mathrm{mg}$ $7-\mathrm{mx}$ in adults is around $20 \mu \mathrm{mol} / \mathrm{l}$ with a half-life of 200 min (unpublished results, SM Ribel-Madsen \& K Trier, 2004). In the rabbit experiment mentioned above [22], peak serum level of $7-\mathrm{mx}$ was around $70 \mu \mathrm{mol} / 1$ and half-life around $1 \mathrm{~h}$.

The 7-mx substance was synthesized by Sigma-Aldrich Co. (Fluka works, Buchs, Switzerland). The tablets were manufactured and packed in a pharmacy certified for pharmaceutical production (Glostrup, Denmark). Participants were asked to bring unused tablets at the end of the follow-up period and the remaining tablets were counted.

\section{Outcome measures}

The primary outcome measure was axial growth rate. Secondary outcome measure was myopia progression.

The axial length was monitored with non-contact, partial coherence interferometer (Zeiss IOL-Master) [28]. The refraction was measured with an autorefractor (Retinomax, Nikon) 30 min after one drop of $1 \%$ cyclopentolate in each eye. In case of astigmatism, half of the astigmatism was added to the sphere. The same Retinomax autorefractor and IOL-Master was used throughout the trial. Measurement stability was confirmed by means of test eyes. Outcome measures were taken four times and the average calculated. 
Weight was measured at base-line, and weight, height, blood pressure, heart rate at the end of the trial, and participants were questioned specifically for CNS, gastrointestinal or cardiopulmonal symptoms.

\section{Sample size}

From a pilot trial, a standard deviation of $0.063 \mathrm{~mm}$ on axial growth per year was found. The smallest difference in mean value of axial growth not to be overlooked was set to $0.050 \mathrm{~mm}$. With an accepted risk of type I error of $5 \%$ and of type II error of $20 \%$, it was calculated that the number of participants needed in each group was 24 .

\section{Randomization}

For the 12-month placebo-controlled trial, participants were randomized in a 1:1 ratio to receive $7-\mathrm{mx}$ or placebo. The allocation sequence was generated in the pharmacy and sealed and numbered containers consecutively handed out to the participants. Outcomes were assessed unaware of group assignment at Trier Research Laboratories. No participants or investigators became unmasked during the first 12 months of the trial.

\section{Statistical methods}

The distribution of demographic data did not deviate substantially from the normal and variances were homogeneous, hence parametric tests were used. For all data on the state and development of myopia was calculated the average of data from each subject's right and left eye, and these average data were subjected to significance tests. The significance of differences between mean values referring to the respective treatment groups was tested with Mann-Whitney test, because of inequality of variances of some of the variables. The significance of differences in axial length or myopia progression rates between periods within the same individual was tested with paired Student's $t$ test. Correlations were analyzed with Pearson's test and proportions with Fisher's exact test.

\section{4-months follow-up}

After completing the 12-month placebo-controlled trial, children from both the placebo and the 7-mx group were given the option of continued treatment with $7-\mathrm{mx} 400 \mathrm{mg}$ either once or twice per day for another 12 months.

36-months follow-up

After completing 24-month follow-up, all participants discontinued treatment with $7-\mathrm{mx}$, and axial growth and myopia progression was followed for another year by measurement at the end of the total of 36 months' follow-up.

\section{Results}

12-month placebo-controlled trial

The 12-month placebo-controlled trial was completed by 77 children.

The reason for not completing was in no case stated as side effects. Compliance among those completing the 12month placebo-controlled trial was $89 \%$ in the $7-\mathrm{mx}$ group versus $92 \%$ in the placebo group. No differences were found as to weight, height, blood pressure, and heart rate. No subjective side effects were reported.

Axial growth rate during the 12-month placebo treatment period was found to be proportional to base-line level $(p<$ 0.01 , Fig. 1). To ensure comparability between the $7-\mathrm{mx}$ and the placebo group, data were therefore compared within two stratification layers, one with a base-line axial growth rate of $0.075-0.190 \mathrm{~mm}$ per 6 months, including 19 treated with $7-\mathrm{mx}$ and 27 treated with placebo, and the other with a base-line axial growth rate of $0.200-0.390 \mathrm{~mm}$ per 6 months, including 16 treated with $7-\mathrm{mx}$ and 15 treated with placebo.

Tables 1 and 2 show axial growth, myopia progression, and change in corneal curvature in the two stratification layers. In both, axial growth was reduced in the 7-mx group compared with the placebo group. The difference was $-0.055 \mathrm{~mm}$ per year $(95 \% \mathrm{Cl}-0.114$ and $+0.005 \mathrm{~mm}$ per year) for children with a moderate base-line axial growth rate $(p=0.073)$, and $-0.031 \mathrm{~mm}$ per year $(95 \% \mathrm{Cl}-0.150$

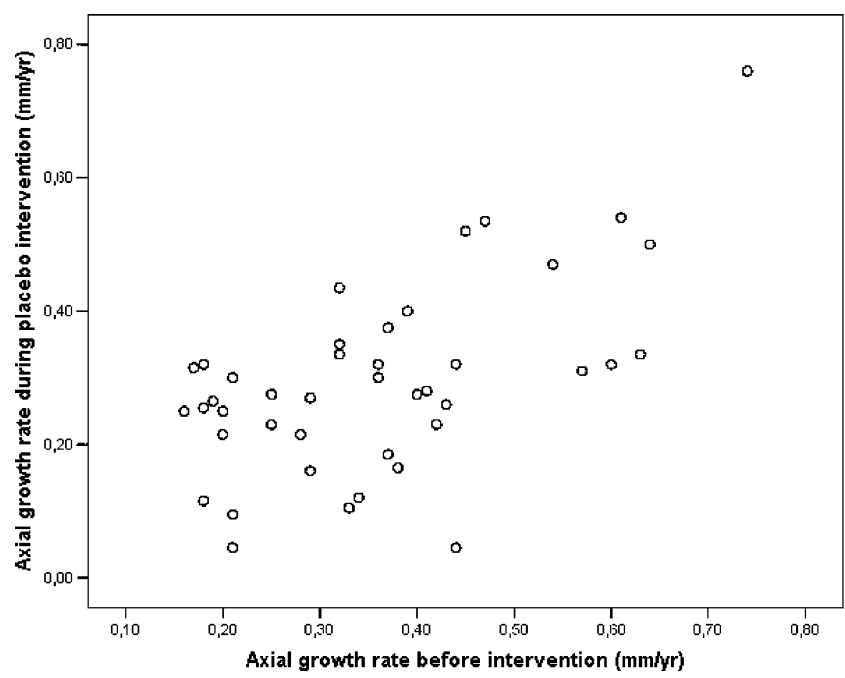

Fig. 1 Correlation between axial length growth-rate during the 12months placebo controlled trial and the observation period before intervention, shown as mean values for right and left eye in each of the participants in the placebo group $(p<0.01)$ 


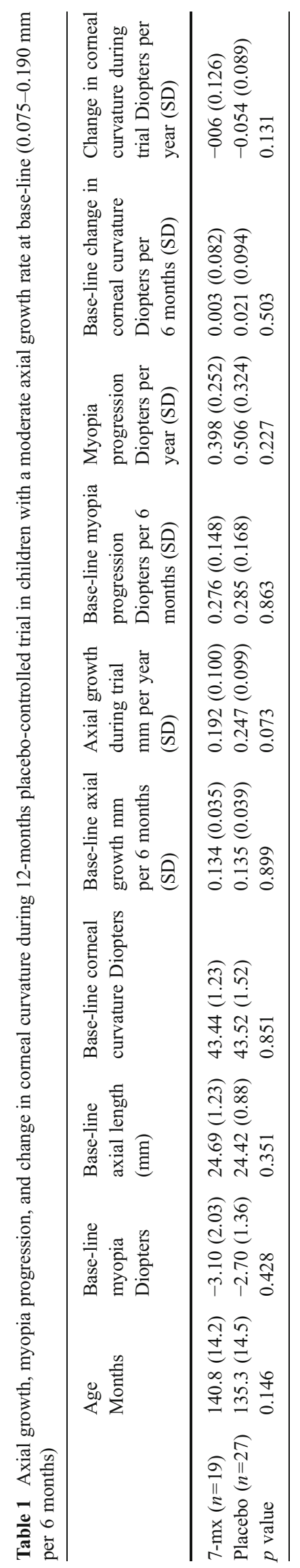

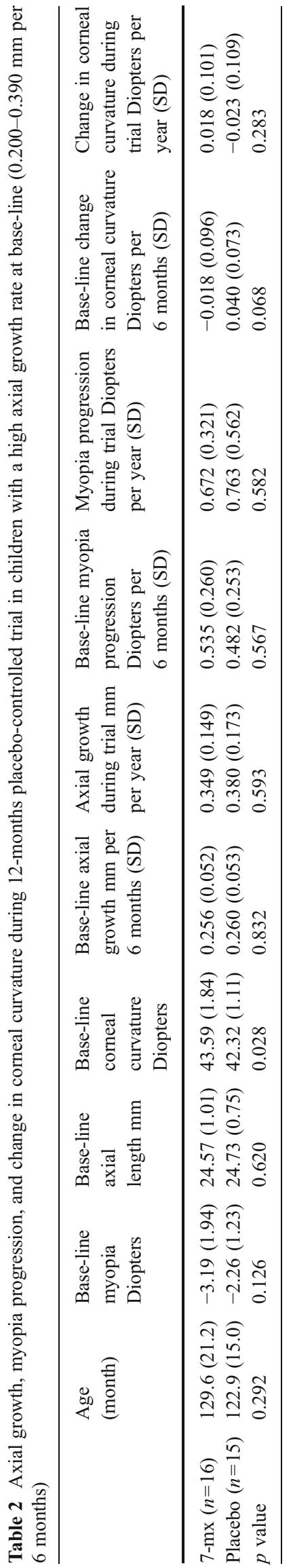


and $+0.087 \mathrm{~mm}$ per year) for children with a high base-line growth rate $(p=0.593)$.

Also the myopia progression was lower in the 7-mx group of both stratification layers, with a difference of -0.108 diopters per year $(95 \% \mathrm{Cl}-0.288$ and +0.070 diopters per year) $(p=$ $0.227)$ and -0.091 diopters per year $(95 \% \mathrm{Cl}-0.424$ and +0.243 diopters per year) $(p=0.582)$, respectively.

\section{4-month follow-up}

The 24-month follow-up period was completed by 68 children. The average daily dose of $7-m x$ taken by each child during the last 12 months of the follow-up ranged from 40 $706 \mathrm{mg}$ per day, average $444 \mathrm{mg}$ per day. No subjective side effects were reported.

Axial growth in children with a moderate base-line axial growth rate $(n=40)$ treated for 24 months with $7-\mathrm{mx}$ was $0.329 \mathrm{~mm}$ (SD $0.143 \mathrm{~mm}$ ) compared with $0.427 \mathrm{~mm}$ (SD $0.193 \mathrm{~mm}$ ) in the group treated with placebo for the first 12 months and with 7-mx for the last 12 months $(p=0.048)$ (Fig. 2). The corresponding axial growth for children with a high base-line axial growth $(n=28)$ was $0.547 \mathrm{~mm}$ (SD $0.212 \mathrm{~mm}$ ) for the 7-mx group, and $0.584 \mathrm{~mm}$ (SD $0.193 \mathrm{~mm}$ ) for the placebo/7-mx group $(p=0.667)$ (Fig. 3).

Myopia progression in children with a moderate baseline axial growth rate $(n=40)$ treated for 24 months with 7$\mathrm{mx}$ was 0.627 diopters (SD 0.329 diopters) compared with 0.844 diopters (SD 0.450 diopters) in the group treated with placebo for the first 12 months and with 7-mx for the last 12 months $(p=0.141)$ (Fig. 4). The corresponding myopia progression for children with a high base-line axial growth $(n=28)$ was 1.131 diopters (SD 0.443 diopters) for the 7$\mathrm{mx}$ group, and 1.010 diopters (SD 0.549 diopters) for the placebo/7-mx group $(p=0.667)$ (Fig. 5).

Percentage myopia stabilization in the period 12 24 months (defined as less than 0.25 diopters myopia progression during the 12 months) is shown in Table 3.

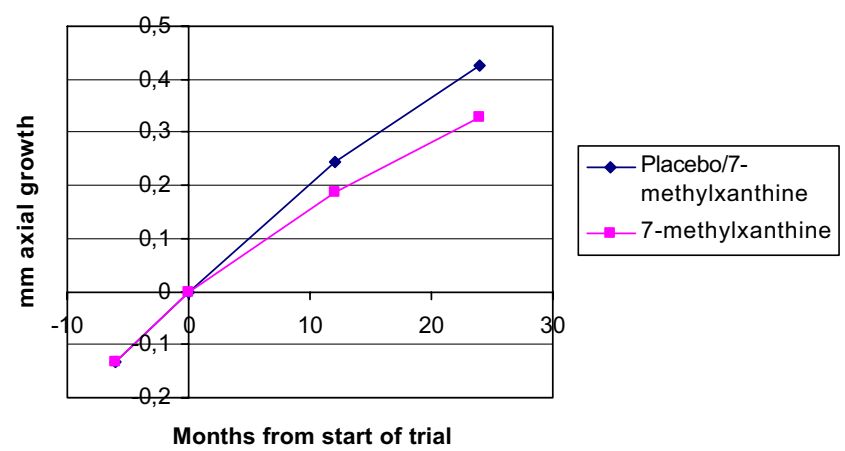

Fig. 2 Axial growth in children with a base-line axial growth rate of $0.075-0.190 \mathrm{~mm}$ per 6 months $(n=40)$. In the period $12-24$ months, both groups received 7-methylxanthine. The difference at 24 months was $-0.098 \mathrm{~mm}(95 \% \mathrm{Cl}-0.211$ and $0.013 \mathrm{~mm}, p=0.048)$

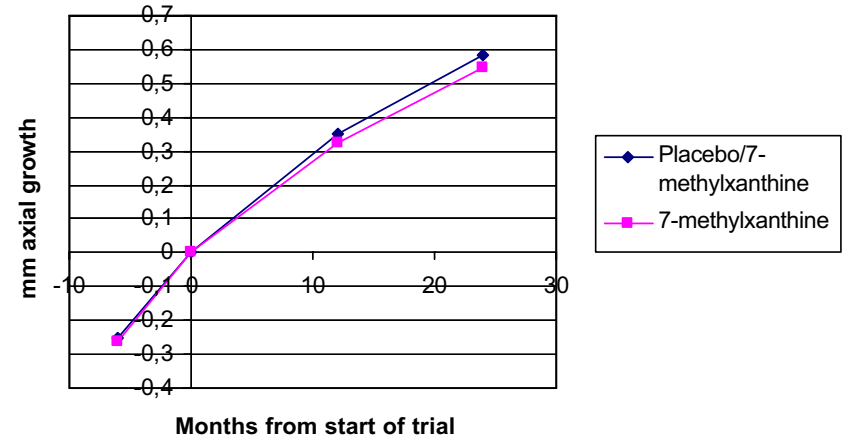

Fig. 3 Axial growth in children with a base-line axial growth rate of $0.200-0.390 \mathrm{~mm}$ per 6 months $(n=28)$. In the period $12-24$ months, both groups received 7-methylxanthine. The difference at 24 months was $-0.037 \mathrm{~mm}(95 \% \mathrm{Cl}-0.195$ and $0.120 \mathrm{~mm}, p=0.667)$

Among children treated for the whole 24-month period with $7-\mathrm{mx}, 59 \%$ of children with a moderate axial growth rate at base-line, and $20 \%$ of children with a high axial growth rate at base-line were stable.

\section{6-month follow-up}

Sixty-one children completed 36-month follow-up. In both the group treated with 7-mx $0-24$ months $(n=28)$ and the group treated with placebo $0-12$ months and $7-\mathrm{mx} 12$ 24 months ( $n=33$ ), axial growth rate in the first as well as the second year of treatment was significantly lower compared with the precedent period $(p<0.00001 / p=0.001$, first year and $p=0.006 / p=0.001$, second year) (Fig. 6a-b). The myopia progression rate, on the other hand, only slowed down in periods with $7-\mathrm{mx}$ treatment $(p<0.0005 / p=0.098$, first year and $p=0.013 / p=0.01$, second year) (Fig. 6c-d). However, in both groups, axial growth rate $(p=0.533 / p=$ $0.179)$ and myopia progression rate $(p=0.162 / p=0.138)$ after discontinuation of the treatment (third year) did not differ significantly from the precedent period (Fig. 6a-d).

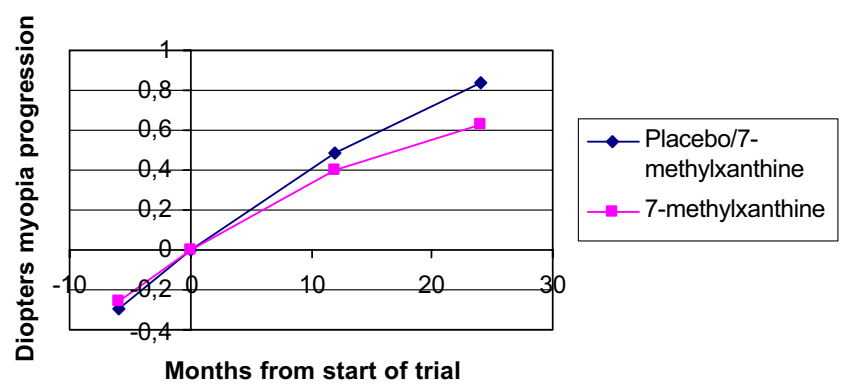

Fig. 4 Myopia progression in children with a base-line axial growth rate of $0.075-0.190 \mathrm{~mm}$ per 6 months $(n=40)$. In the period $12-$ 24 months, both groups received 7-methylxanthine. The difference at 24 months was -0.217 diopters $(95 \% \mathrm{Cl}-0.478$ and 0.044 diopters, $p=0.141$ ) 


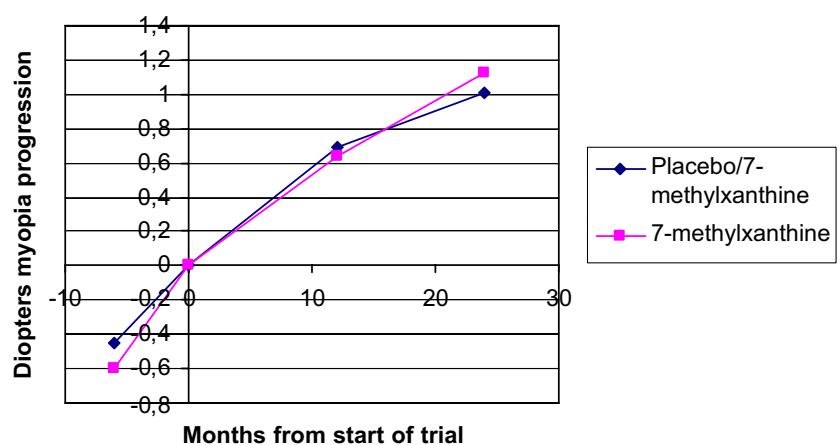

Fig. 5 Myopia progression in children with a base-line axial growth rate of $0.200-0.390 \mathrm{~mm}$ per 6 months $(n=28)$. In the period $12-$ 24 months, both groups received 7-methylxanthine. The difference at 24 months was 0.121 diopters $(95 \% \mathrm{Cl}-0.267$ and 0.508 diopters, $p=$ $0.541)$

\section{Discussion}

In this study, base-line axial growth rate was taken into consideration when comparing inter-group differences in axial growth. The rate of myopia progression is believed to be the most important variate as regards base-line comparability [29]. The finding of a significant correlation between axial growth at base-line and axial growth in the first 12 months of the intervention period supports the importance of using the axial growth rate as one of the inclusion criteria in myopia studies. Frequency of contact lens wear was close to equal in the 7-mx group and the placebo group $(17 \%$ versus $19 \%$ during the 12 -months trial). Contact lens wear does not seem to affect the growth of the vitreous chamber significantly [30].

The degree of under-correction in the participants was not recorded in this trial, and could therefore theoretically be a confounding factor. One study found that undercorrection enhances myopia progression [31], while another found no effect [32]. It is not known whether the axial growth rate is affected by under-correction.

At 12 months, the lowest axial growth in both stratification layers was found in the 7-mx groups, but the differences were not significant.

At 24 months, however, a significantly lower axial growth was found in children with a moderate base-line axial growth rate treated for all 24 months with 7-mx compared with those treated with placebo for the first 12 months and 7-mx for the last 12 months (difference $0.098 \mathrm{~mm}$ ), whereas the difference among children with a high base-line axial growth rate $(0.037 \mathrm{~mm})$ was non-significant.

Children with a high base-line axial growth rate $(0.200-$ $0.390 \mathrm{~mm}$ per 6 months) have a myopia progression of up to 2 diopters per year. Such severely progressing myopia is frequently linked to specific genetic abnormalities, and may therefore represent a sub-group, possibly more refractory to treatment than the majority of myopes.
Nevertheless, in the second year of the intervention period, average axial growth among children with a high base-line axial growth rate treated for all 24 months with 7$\mathrm{mx}$, was reduced to $0.22 \mathrm{~mm}$ per year from an initial $0.52 \mathrm{~mm}$ per year at base-line. This is lower than the expected average axial growth rate of $0.25 \mathrm{~mm}$ per year for age-matched Danish myopes, including low-, moderate-, and high-progressors [33]. The corresponding myopia progression rate in the second year of the intervention period among children with a high base-line axial growth rate treated for all 24 months with $7-\mathrm{mx}$ was reduced to 0.49 diopters per year from 1.20 diopters per year at baseline. The expected average myopia progression rate for agematched Danish myopes, including low-, moderate-, and high-progressors is 0.48 diopters per year [33]. For children with a moderate axial growth rate at base-line $(0.075-$ $0.190 \mathrm{~mm}$ per 6 months), treated for all 24 months with 7 $\mathrm{mx}$, axial growth rate was reduced to $0.14 \mathrm{~mm}$ per year in the second year of treatment from $0.27 \mathrm{~mm}$ per year at base-line, and the myopia progression rate to 0.23 diopters per year in the second year of treatment from 0.52 diopters per year at base-line. Thus, in comparison to the average of age-matched Danish myopes, including low-, moderate-, and high-progressors [33], both axial growth and myopia progression was reduced by around $50 \%$ in the second year of treatment with 7-mx.

In an unselected material of myopes, the percent with stable myopia increased with age from 14\% for 12-yearolds to $63 \%$ for 18 -year-olds [34]. In comparison, our finding of a markedly higher percentage of stable myopia (59\% and $21 \%$, moderate and high base-line axial growth rate respectively) in the second year of treatment, further supports that treatment with 7-mx stabilizes myopia.

In the age interval 11-14 years, myopia progression and axial elongation is close to linear [14]. A decrease in both myopia progression rate and axial elongation rate during both the first and the second year of treatment with 7-mx is therefore unexpected. The absence of a further reduction of

Table 3 Myopia stabilization in the period 12-24 months

\begin{tabular}{lcc}
\hline & $\begin{array}{l}\text { Base-line axial } \\
\text { growth } 0.075- \\
0.190 \mathrm{~mm} \text { per } \\
6 \text { months }\end{array}$ & $\begin{array}{l}\text { Base-line axial } \\
\text { growth } 0.200- \\
0.390 \mathrm{~mm} \text { per } \\
6 \text { months }\end{array}$ \\
\hline $\begin{array}{l}\text { Placebo 12 months/ } \\
7 \text {-methylxanthine } \\
12 \text { months } \\
7 \text {-methylxanthine } \\
24 \text { months } \\
p \text { value }\end{array}$ & $35 \%$ & $21 \%$ \\
\hline
\end{tabular}



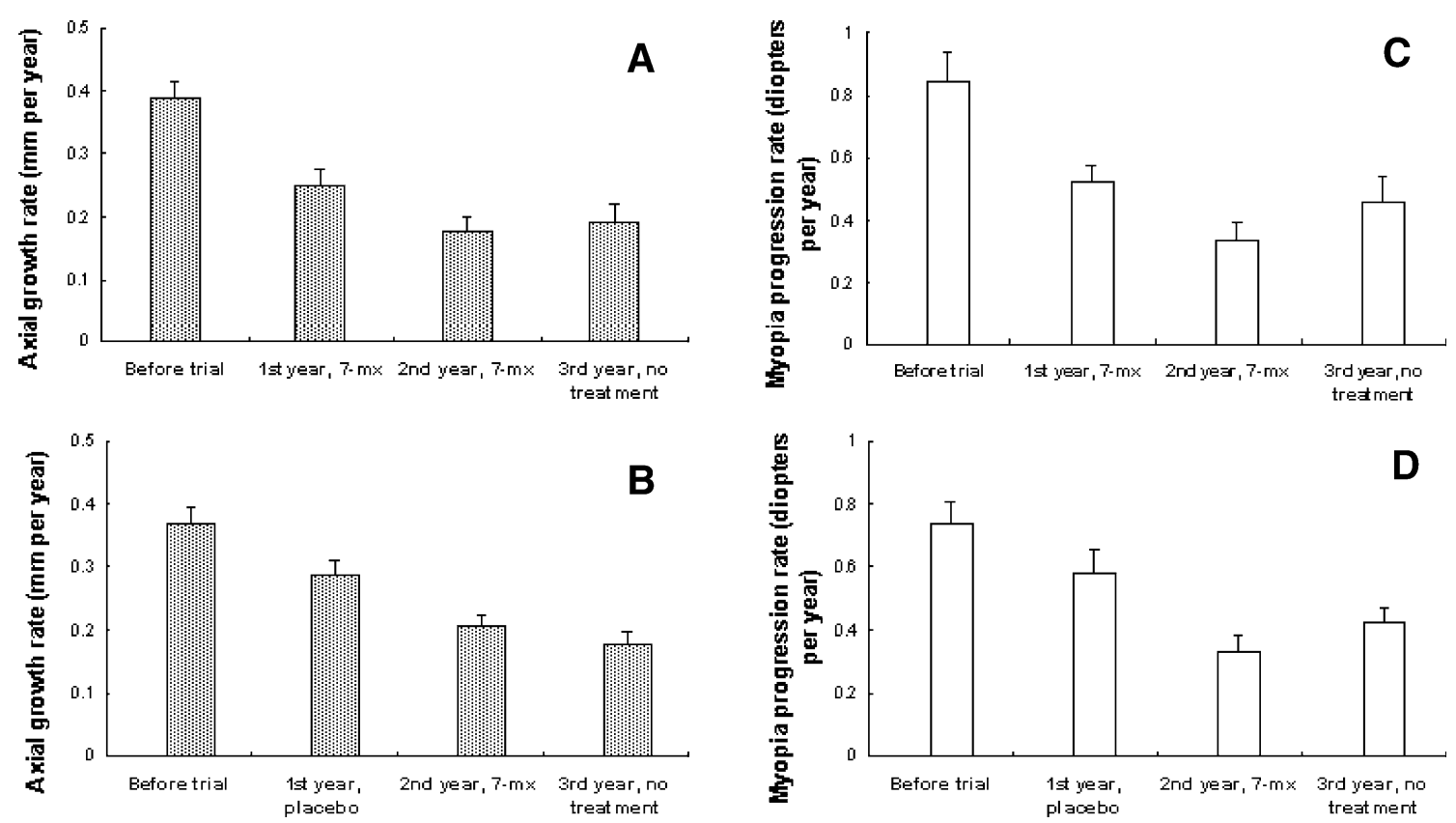

Fig. 6 a, b Axial growth rate before trial, during treatment with 7-mx or placebo in the first year, during treatment with $7-\mathrm{mx}$ in the second year, and after discontinuation of treatment. In the first and second year, axial growth rate is significantly lower than in the precedent period, but in the third year, after discontinuation of treatment, axial

growth rate is not different from the precedent year. c, d Myopia progression rate in the same periods. The myopia progression rate is significantly reduced compared with the precedent period during treatment with 7-mx, but unchanged in periods with placebo treatment or no treatment

myopia progression and axial elongation in the third year coincides with the discontinuation of treatment and is consistent with the treatment being efficient.

Methylxanthines in non-toxic doses block adenosine receptors (ADOR) competitively. Adenosine in the concentrations found under physiological conditions activates primarily $\mathrm{A} 1$ and $\mathrm{A} 2 \mathrm{~A}$ adenosine receptors (ADORA1 and ADORA2A) on the cell surface. ADORA1s are widely distributed in the CNS, whereas ADORA2As are found mainly in the dopamine-rich regions of the brain [35].

Adenosine has a general homeostatic role in the regulation of cell metabolism, but also a specific neuromodulatory role with ADORA1s having an inhibitory role and ADORA2As having a facilitatory role in the release of neurotransmitters such as dopamine, noradrenalin, acetylcholine, glutamate, and serotonin [36]. ADORA1s and ADORA2As have been localized in the ciliary body and the retina and ADORA2As in the retinal pigment epithelium of adult rats [37] and humans (unpublished results, Zhongshan Ophthalmic Center). Both ADORA1s and ADORA2As are expressed in human scleral fibroblasts [38].

Experimental myopia in animals has been linked to changes in retinal dopamine and acetylcholine neurotransmission [39-44]. Both of these neurotransmitters are modulated by ADORs [45-50]. The mechanism by which 7-mx affects eye elongation and myopia progression could therefore theoretically involve modulation of muscarinic acetycholine or dopamine receptors. On the other hand, it is also possible that ADORs are directly involved in the control of eye growth. Because of receptor adaptation, the effects related to blocking of ADOR1s are attenuated during chronic treatment with non-selective ADOR antagonists like 7-mx, whereas effects related to blocking of ADORA2As are unchanged [51-53].

Adenosine liberated from the retina is believed to activate ADORA2s on the retinal pigment epithelium and augment the standing potential (SP) [54]. The effect on the SP might therefore give us a measure of the potency of a specific methylxanthine as a blocker of adenosine receptors. The receptor affinity of $7-\mathrm{mx}$ is three to five times higher than theobromine [55]. Correspondingly, the lightrise of SP in humans is more reduced by $7-\mathrm{mx}$ than by theobromine (unpublished results, K Trier, 2004). Interestingly, high ametropia in children is associated with retinal electrophysiological abnormalities, a finding consistent with the hypothesis that the retina is involved in the process of emmetropization [56].

In conclusion, systemic treatment with 7-mx appears to be efficient in retarding axial elongation and myopia progression among myopic children. The treatment is safe and without side effects, and may be continued until 1820 years of age, when age-related cross-linking of collagen prevents further elongation of the eye. 
Acknowledgments This work was supported by grants from "Jørgen Bagenkop Nielsens Myopi-Fond" and "Generalkonsul Einar Høyvalds Fond”, and by “Øjenlæge Klaus Trier ApS”.

Ethics approval Approval of the trial has been obtained from the Danish Medicines Agency and the Ethics Committee for the municipality of Copenhagen and Frederiksberg (KF 02-042/03).

Open Access This article is distributed under the terms of the Creative Commons Attribution Noncommercial License which permits any noncommercial use, distribution, and reproduction in any medium, provided the original author(s) and source are credited.

\section{References}

1. McBrien NA, Gentle A. Role of sclera in the development and pathological complications of myopia. Prog Ret Eye Res. 2003;22:307-38.

2. Guggenheim JA, McBrien NA. Form-deprivation myopia induces activation of scleral matrix metalloproteinase-2 in tree shrew. Invest Ophthalmol Vis Sci. 1996;37:1380-95.

3. Jobling A, Nguyen M, Gentle A, et al. Isoform-specific changes in scleral TGF- $\beta$ expression and the regulation of collagen synthesis during myopia progression. J Biol Chem. 2004;279:18121-6.

4. Jones LA, Mitchell GL, Mutti DO, et al. Comparison of ocular component growth curves among refractive error groups in children. Invest Ophthalmol Vis Sci. 2005;46:2317-27.

5. Thorn F, Gwiazda J, Held R. Myopia progression is specified by a double exponential growth function. Opt Vis Sci. 2005;82:E286.

6. Baily AJ, Paul RG, Knott L. Mechanisms of maturation and ageing of collagen. Mech Age Dev. 1998;106:1-56.

7. Atchison DA, Jones CE, Schmid KL, et al. Eye shape in emmetropia and myopia. Invest Ophthalmol Vis Sci. 2004; 45:3380-6.

8. Polkinghorne PJ, Craig JP. North New Zealand rhegmatogenous retinal detachment study: epidemiology and risk factors. Clin Exp Ophthalmol. 2004;32:159-63.

9. Saw SM, Gazzard G, Au Eong KG. Myopia: attempts to arrest progression. Br J Ophthalmol. 2002;86:1306-11.

10. Fan DSP, Lam DSC, Chan CKM, et al. Topical atropine in retarding myopia progression and axial length growth in children with moderate to severe myopia: A pilot study. Jpn J Ophthalmol. 2007;51:27-33.

11. Siatkowski RM, Cotter S, Crockett RS et al Two-year multicenter, double-masked, placebo-controlled, parallel safety and efficacy study of $2 \%$ pirenzepine ophthalmic gel in children with myopia. J AAPOS. 2008;12:332-9.

12. Tan DTH, Lam DS, Chua WH, et al. One-year multicenter, double-masked, placebo-controlled, parallel safety and efficacy study of $2 \%$ pirenzepine ophthalmic gel in children with myopia. Ophthalmology 2005;112:84-91.

13. Yin GC, Gentle A, McBrien NA. Muscarine antagonist control of myopia: A molecular search for the M1 receptor in chicks. Mol Vis. 2004;10:787-93.

14. Scott JE. Dermatan Sulphate Proteoglycans. London: Portland Press; 1993.

15. Bailey AJ. Structure, function and ageing of the collagens of the eye. Eye 1987;1:175-83

16. Parry DA. The molecular and fibrillar structure of collagen and its relationship to the mechanical properties of connective tissue. Biophys Chem. 1988;29:195-209.
17. Avetisov ES, Savitskaya NF, Vinetskaya MI, et al. A study of biochemical and biomechanical properties of normal and myopic eye sclera in humans of different age groups. Metab Pediatr Syst Ophthalmol. 1984;7:183-8.

18. Rada JA, Nickla DL, Troilo D. Decreased proteoglycan synthesis associated with form deprivation myopia in mature primate eyes. Invest Ophthalmol Vis Sci. 2000;41:2050-8.

19. McBrien NA, Lawlor P, Gentle A. Scleral remodeling in the development and recovery from axial myopia in the tree shrew. Invest Ophthalmol Vis Sci. 2000;41:3713-9.

20. McBrian A, Cornell LM, Gentle A. Structural and ultrastructural changes to the sclera in a mammalian model of high myopia. Invest Ophthalmol Vis Sci. 2001;42:2179-87.

21. Funata M, Tokoro T. Scleral changes in experimentally myopic monkeys. Graefe's Arch Clin Exp Ophthalmol. 1990;228:174-9.

22. Trier K, Olsen EB, Kobayashi $\mathrm{T}$, et al. Biochemical and ultrastructural changes in rabbit sclera after treatment with 7 methylxanthine, theobromine, acetazolamide or L-ornithine. Br J Ophthalmol. 1999;83:1370-5.

23. Cui D, Trier K, Chen X et al. Effects of 7-methylxanthine on form deprived myopia in guinea pig. In ARVO annual meeting, Ft. Lauderdale, FL; 2008.

24. Tarka SM Jr. The toxicology of cocoa and methylxanthines: a review of the literature. Crit Rev Toxicol. 1982;9:275-312.

25. Tarka SM Jr, Morrissey RP, Apgar JL. Chronic toxicity/carcinogenecity studies of the cocoa powder in rats. Food Chem Toxicol. 1991;29:7-19.

26. IARC. Monographs on the evaluation of the carcinogenic risk of chemicals to man. Geneva: WHO, International Agency for Research on Cancer, 1972-present; 1991. p. 51-357.

27. Zadnik K. Myopia development in childhood. Optom Vis Sci. 1997;74:603-8.

28. Carkeet A, Saw SM, Gazzard G, et al. Repeatability of IOLMaster biometry in children. Optom Vis Sci. 2004;81:829-34.

29. Khoo C, Ng R. Methodologies for interventional myopia studies. Ann Acad Med. 2006;35:282-6.

30. Fulk GW, Cyert LA, Parker DE, et al. The effect of changing from glasses to soft contact lenses on myopia progression in adolescents. Ophthal Physiol Opt. 2003;23:71-7.

31. Chung K, Mohidin N, O'Leary DJ. Undercorrection of myopia enhances rather than inhibits myopia progression. Vis Res. $2002 ; 42: 2555-9$.

32. Ong E, Grice K, Held R, et al. Effects of spectacle intervention on the progression of myopia in children. Optom Vis Sci. 1999;76:363-9.

33. Jensen H. Myopia progression in young school children. Acta Ophthalmologica Suppl. 1991;69:1-79.

34. Dong L, Gwiazda J, Hyman L et al. (2007) Myopia stabilization in the correction of myopia evaluation trial (COMET) cohort. In ARVO annual meeting, Ft. Lauderdale, FL

35. Fredholm BB, Bättig K, Holmen J, et al. Actions of caffeine in the brain with special reference to factors that contribute to its widespread use. Pharmacol Rev. 1999;51:83-133.

36. Cunha RA. Adenosine as a neuromodulator and as a homeostatic regulator in the nervous system: different roles, different sources and different receptors. Neurochem Int. 2001;38:107-25.

37. Kvanta A, Seregard S, Sejersen S, et al. Localization of adenosine receptor messenger RNAs in the rat eye. Exp Eye Res. 1997;65:595-602.

38. Cui D, Trier K, Chen X, et al. Distribution of adenosine receptors in human sclera fibroblasts. Mol Vis. 2008;14:523-9.

39. Liu Q, Wu J, Wang X, et al. Changes in muscarinic acetylcholine receptor expression in form deprivation myopia in guinea pigs. Mol Vis. 2007;13:1234-44.

40. Iuvone PM, Tigges M, Stone RA, et al. Effects of apomorphine, a dopamine receptor agonist, on ocular refraction and axial 
elongation in a primate model of myopia. Invest Ophthalmol Vis Sci. 1991;32:1674-7.

41. McBrien NA, Cottriall CL, Annies R. Retinal acetylcholine content in normal and myopic eyes: a role in ocular growth control? Vis Neurosci. 2001;18:571-80.

42. Gao Q, Liu Q, Ma P, et al. Effects of direct intravitreal dopamine injections on the development of lid-suture induced myopia in rabbits. Graefes Arch Clin Exp Ophthalmol. 2006;244:1329-35.

43. Ouyang CH, Chu RY, Hu WZ. Effects of pirenzepine on lensinduced myopia in the guinea-pig. Zhonghua Yan Ke Za Zhi. 2003;39:348-51.

44. Cottriall CL, McBrien NA. The M1 muscarinic antagonist pirenzepine reduces myopia and eye enlargement in the tree shrew. Invest Ophthalmol Vis Sci. 1996;37:1368-79.

45. Cunha RA. Adenosine as a neuromodulator and as a homeostatic regulator in the nervous system: different roles, different sources and different receptors. Neurochem Int. 2001;38:107-25.

46. Salmi P, Chergui K, Fredholm BB. Adenosine-dopamine interactions revealed in knockout mice. J Mol Neurosci. 2005;26:239-44.

47. Oliveira L, Correia-de-Sa P. Protein kinase A and Ca(v)1 (L-Type) channels are common targets to facilitatory adenosine A2A and muscarinic M1 receptors on rat motoneurons. Neurosignals 2005; $14: 262-72$.

48. Marks GA, Shaffery JP, Speciale SG, et al. Enhancement of rapid eye movement sleep in the rat by actions at $\mathrm{A} 1$ and $\mathrm{A} 2 \mathrm{a}$ adenosine receptor subtypes with a differential sensitivity to atropine. Neuroscience 2003;116:913-20.
49. El Yacoubi M, Ledent C, Parmentier M, et al. Adenosine A2A receptor knockout mice are partially protected against druginduced catalepsy. Neuroreport 2001;12:983-986.

50. Moo-Puc RE, Góngora-Alfaro JL, Alvarez-Cervera FJ, et al. Caffeine and muscarinic antagonists act in synergy to inhibit haloperidolinduced catalepsy. Neuropharmacology 2003;45:493-503.

51. Shi D, Daly JW. Chronic effects of xanthines on levels of central receptors in mice. Cell Mol Neurobiol. 1999;19:719-32.

52. White PJ, Nguyen TT. Chronic caffeine treatment causes changes in cardiac Adenosine receptor function in rats. Pharmacology 2002;65:129-35.

53. Quarta D, Ferré S, Solinas M, You ZB, Hockemeyer J, Popoli P, Goldberg SR. Opposite modulatory roles for adenosine A1 and $\mathrm{A} 2 \mathrm{~A}$ receptors on glutamate and dopamine release in the shell of the nucleus accumbens. Effect of chronic caffeine exposure. J Neurochem. 2004;88:1151-8.

54. Gallemore RP, Hughes BA, Miller SS. Light-induced responses of the retinal pigment epithelium. In: Marmor MF, Wolfensberger TJ, editors. The retinal pigment epithelium. New York: Oxford University Press; 1998. p. 175-198.

55. Müller CE, Shi D, Manning M, et al. Synthesis of paraxanthine analogs (1,7-disubstituted xanthines) and other xanthines unsubstituted at the 3-position: structure-activity relationship at adenosine receptors. J Med Chem. 1993;36:3341-9.

56. Flitcroft DI, Adams GG, Robson AG, et al. Retinal dysfunction and refractive errors: an electrophysiological study of children. $\mathrm{Br}$ J Ophthalmol. 2005;89:484-8. 